\title{
A honey bee (Apis mellifera) colony's brood survival rate predicts its in vitro-reared brood survival rate
}

\author{
Ashley N. Mortensen ${ }^{1,2}$, James D. Eluis ${ }^{1}$ \\ ${ }^{1}$ Honey Bee Research and Extension Laboratory, Entomology \& Nematology Department, University of Florida, Bldg \\ 970 Natural Area Drive, Gainesville, FL 32611, USA \\ ${ }^{2}$ The New Zealand Institute for Plant \& Food Research Limited, Private Bag 3230, Waikato Mail Centre, Hamilton 3240, \\ New Zealand
}

Received 8 December 2017 - Revised 21 May 2018 - Accepted 19 July 2018

\begin{abstract}
Rearing honey bee, Apis mellifera L., larvae in vitro is a popular risk assessment tool because many uncontrollable factors (e.g., weather conditions, food availability) that bias field studies can be eliminated in the laboratory. However, modern in vitro rearing techniques suffer variable survival rates and OECD guidelines specify a minimum of $70 \%$ survival to adult emergence in the untreated negative controls for the test to be considered valid. We hypothesized that the colony from which larvae are sourced for in vitro-rearing risk assessments may affect the survival percentage of those larvae in vitro. To test this hypothesis, we compared the survival rates of brood reared in vitro to that of brood reared by their parental colony to determine if source colony affects brood survival in vitro. Colony-reared and in vitro- reared brood survival percentages were calculated for each of the 14 colonies. There was not a statistically detectable difference in the survival percentage to adult emergence of colony-reared and in vitroreared bees. Furthermore, the colony-reared brood survival percentage at day 11 (prepupal stage) was predictive of the survival percentage to adult emergence of in vitro-reared bees. We suggest that the 11-day brood survival percentage should be used when selecting suitable colonies for use as source colonies for in vitro-rearing risk assessments. Based on our results, colonies with brood survival percentages of $\geq 80 \%$ are suitable colonies from which to source larvae for in vitro-rearing risk assessments.
\end{abstract}

Apis mellifera / honey bee / in vitro / brood / rearing

\section{INTRODUCTION}

Increased honey bee colony losses (Neumann and Carreck 2010) and dramatic pollinator decline (Lebuhn et al. 2013) are occurring internationally. Parasites, pathogens, poor nutrition, queen quality, and pesticides are considered significant colony stressors and likely contributing causes to colony losses. A substantial amount of research has focused on determining the extent to which these stressors affect honey bee health (Chauzat et al.

Corresponding author: A. Mortensen, Ashley.Mortensen@plantandfood.co.nz Manuscript editor: Monique Gauthier
2006; Higes et al. 2008; Le Conte et al. 2010; Mullin et al. 2010; vanEngelsdorp et al. 2010; Martin et al. 2012; Steinhauer et al. 2014).

Pesticides and pathogens generally are regarded as primary factors affecting honey bee colony health (Neumann and Carreck 2010; Mullin et al. 2010; Medrzycki et al. 2013). Standard methods for investigating pesticide and pathogen effects on adult honey bees at the field and laboratory level have been well-vetted (Alix et al. 2010; Medrzycki et al. 2013), though potential effects of pesticides on developmental stages often are overlooked. Some field evaluations do include parameters such as total brood area (Delaplane et al. 2013). However, experiments conducted within a honey bee colony are biased by many uncontrolled factors such as resource 
availability, season, climate, and colony genetics (Hendriksma et al. 2011). Much of this bias can be overcome using in vitro rearing techniques for honey bees (Hendriksma et al. 2011; Crailsheim et al. 2013). Furthermore, in vitro rearing is useful when studying honey bee development and caste differentiation (Woyke 1963; Rembold and Lackner 1981; Asencot and Lensky 1984; Brouwers 1984; Crailsheim et al. 2013; Buttstedt et al. 2016).

Rudimentary in vitro rearing techniques were first used to study caste differentiation in honey bees in 1933 (Crailsheim et al. 2013). In 1981, an in vitro rearing protocol was suggested as a potential risk assessment tool that could be used to test the toxicity of pesticides to worker bee larvae (Wittmann and Engels 1981). However, early in vitro rearing techniques were plagued by poor survival of grafted larvae to adult emergence and inconsistent caste determination of the emerging adults. Since that time, several in vitro rearing protocols that offer acceptable survival success have been developed (Vandenberg and Shimanuki 1987; Peng et al. 1992; Aupinel et al. 2005; Crailsheim et al. 2013). Recently, Schmehl et al. (2016) improved upon these protocols, consistently achieving adult emergence rates well above the OECD minimum of $>$ $70 \%$ survival (OECD 2015).

Despite improved in vitro rearing protocols, variability in survival success continues to be reported within and between laboratories (Aupinel et al. 2010). Larvae that are grafted for in vitro risk assessments often come from a small number of source colonies (i.e., three or fewer colonies). Furthermore, the same source colonies are not always used between replicates or experiments over time. We suspected that the source colony from which one-day-old larvae are collected influences the survival percentages seen in experiments conducting in vitro rearing. To test this prediction, we designed a study to evaluate the survival rates of larvae from numerous source colonies in two rearing environments: their parental hive and in vitro.

\section{MATERIALS AND METHODS}

In June-July (summer) of 2015, SeptemberOctober (fall) 2015, and April-May (spring) of
2016, the survival rates of larvae reared in their parental hives were calculated and compared to the survival rates of larvae from the same parental hives reared in vitro. All colonies were housed in the University of Florida apiary in Gainesville, Florida $\left(29^{\circ} 37^{\prime} 38.81^{\prime \prime} \mathrm{N}, 82^{\circ} 21^{\prime} 23.16^{\prime \prime} \mathrm{W}\right)$. Each colony was headed by a European-derived queen (Sheppard 1989). All hives were composed of a single, 10-frame Langstroth hive body, and managed according to regional best management practices throughout the duration of the study (FDACS 2013). Colonies were fed 50\% weight:volume sucrose solution prior to and throughout each trial period as nectar is not plentiful in the area. No protein supplementation was provided.

\subsection{Brood isolation}

To initiate a trial, a queen was confined to a patch of empty brood comb (patch A) as described by Schmehl et al. (2016). Twenty-four hours later (D1), the queen was relocated to a new frame and confined to another patch of empty brood comb (patch B) for an additional $24 \mathrm{~h}$. After the second confinement, the queen was released back into the hive and the confinement cages replaced onto both brood patches to ensure that no additional eggs were laid in those areas. For each colony, brood patch A was randomly assigned to either the colony-reared or in vitro-reared groups. Brood patch B was assigned the opposite rearing environment (e.g., if brood patch A was designated colony-reared, then brood patch B was assigned in vitro-reared and vice versa).

\subsection{Colony rearing assay}

On D4, the confinement cage was removed and a piece of clear acetate $(21.59 \mathrm{~cm} \times 28 \mathrm{~cm})$ was overlaid on the brood patch (Human et al. 2013). A section of brood from within the patch was outlined and empty cells were denoted on the acetate sheet. The total number of cells that contained larvae was determined, the acetate sheet removed, and the frame returned to the parental hive. Prepupal survival was assessed on D11 by replacing the acetate sheet over the section of brood that was profiled on D4 and noting any 
cells that had previously contained a larva, but were then empty. The number of cells that still contained viable brood was determined, the acetate sheet removed, and the frame returned to the parental hive. On D18, the frame containing the brood patch was collected from the hive and transported to the laboratory. The acetate sheet was again overlaid on the same section of brood that was profiled on D4 and 11 and any cells that had previously contained brood, but were now empty, were noted. Screen push-in cages were then placed over the brood patch and the frame placed in an incubator maintained at $35^{\circ} \mathrm{C}$ and $50 \%$ R.H. for 3 days (Human et al. 2013). On D21, the frame was removed from the incubator, the push-in cage removed from the frame, and the total number of cells from which bees had emerged counted. Any cells from which bees had not emerged were opened manually to confirm that the individual inside was not viable. In total, brood survival percentages were calculated at D11 for 25 colonies and at adult emergence for 14 colonies. All survival percentages were calculated based on the number of individuals alive on D4.

\subsection{In vitro rearing assay}

In vitro larval rearing was performed as described by Schmehl et al. (2016). In short, frames containing a patch of 1-day-old larvae were collected from the colony on D4 and transported to the laboratory. The larvae were transferred from the comb to prepared sterile tissue culture plates containing $20 \mu \mathrm{l}$ of artificial diet and maintained in an incubator at $35^{\circ} \mathrm{C}$ and $\sim 94 \%$ R.H. Each larva was fed 20, 30, 40, and $50 \mu \mathrm{l}$ of artificial diet on $\mathrm{D} 6,7,8$, and 9, respectively. The larvae were then transferred to another prepared sterile tissue culture plate for pupation once they had consumed all of the diet (between D10 and D12). The pupation plates were incubated at $35{ }^{\circ} \mathrm{C}$ and $\sim 75 \%$ R.H. Each larva was visually inspected every day. Any dead individuals were immediately removed from the plate at each inspection and the total number of surviving individuals recorded. Adults were counted and removed from the pupation plate as they emerged (D21-D23). In vitro rearing survival percentages were calculated at D11 and at adult emergence for 25 colonies. All survival percentages were calculated based on the number of individuals alive on D4 (i.e., the number of grafted individuals).

\subsection{Statistical analysis}

Survival percentages were analyzed using generalized linear mixed models methodology as implemented in SAS PROC GLIMMIX (SAS/STAT 14.1; SAS Institute, Cary, NC) using the binomial distribution function with the default logit link function. Rearing environment (colony, in vitro), time (D11, adult emergence), and the interaction between the two were considered fixed effects. Experimental repeat, colony (experimental repeat), and the interaction of treatment with colony (experimental repeat) were considered random effects, the latter serving as the proper error term to test treatment. The residual covariance structure was modeled using various structures but none were able to improve the generalized chi-square/ df ratio fit statistics of 0.92 . This indicates a good fit of the random model and no indication of overdispersion. Interaction means were generated using the LSMEANS command in the abovementioned PROC and pairwise contrasts performed. Means and standard errors were back-transformed using the ilink option of the LSMEANS command. Final survival data were regressed on initial survival proportion (D11) within a generalized linear mixed models environment. Predicted mean survival values were generated and plotted against initial survival.

\section{RESULTS}

Percent survival means, standard error, and $N$ (number of parental colonies) were as follows: $89 \%( \pm 2.5, N=25)$ to D11 in the parental hive, $84.9 \%( \pm 3.4, N=14)$ to adult emergence in the parental hive, $93 \%( \pm 1.8, N=25)$ to D11 in vitro, and $84.9 \%( \pm 3.3, N=25)$ to adult emergence in vitro. There was a statistically detectable difference between rearing environments (in vitro or colony) for survival percentage based on the time point (D11 or adult emergence) $(\mathrm{F}=8.5, \mathrm{df}=85$, $p=0.004)$. There was a statistically detectable decrease in mean survival percentage from D11 
to adult emergence for brood reared within both rearing environments (colony: $p=0.002$, in vitro: $p>0.001)$. Furthermore, survival to D11 was significantly higher for brood reared in vitro than in the parental hive $(p=0.013)$. However, there was not a statistically detectable difference between in vitro and colony survival percentages at adult emergence ( $p=0.996$; Table I).

Day 11 colony survival percentage is predictive of adult emergence percentage within both rearing environments (Figure 1). The plots of adult emergence survival percentage by day 11 survival percentage for both colony-reared and in vitro-reared bees have the same slope $(5.1 \pm 0.6,95 \%$ CI (3.9, $6.4), p<0.001)$. The intercept of the colonyreared day 11 and adult emergence survival percentage relationship is $-2.8 \pm 0.5$ (95\% CI ( -3.9 , $-1.7), p<0.001)$, and the intercept of the in vitroreared day 11 and adult emergence survival percentage relationship is $-3 \pm 0.5$ (95\% CI $(-4.2$, $1.9), p<0.001)$. Furthermore, colony survival to day 11 is predictive of the in vitro adult emergence rate (slope $=3.3 \pm 0.7,95 \% \mathrm{CI}(1.9,4.7), p<$ 0.001 ; intercept $=-1.2 \pm 0.6,95 \%$ CI $(-2.4,0)$, $p=0.048$ ) (Figure 2).

\section{DISCUSSION}

Individual variation is well-documented throughout the natural world (Houle 1992; Lynch and Walsh 1997; Nettle 2006). Furthermore, colony-level variation in honey bees for parameters such as adult behavior and morphology is also well-documented (Breed and Rogers 1991; Meixner et al. 2013; Pirk et al. 2013;
Scheiner et al. 2013; De Souza et al. 2015). Correspondingly, multiple source colonies are recommended for use in laboratory risk assessments to account for colony-level differences in stress responses (Alix et al. 2010; Crailsheim et al. 2013; OECD 2015). While the effect of colony-level variation is recognized in the physiological response of bees to stressors such as pathogens and pesticides, the impact of colony-level variation on survival to adult emergence has been disregarded in in vitro rearing protocols. Moreover, colony-level variation in survival has been overlooked throughout the extensive effort to improve survival rates in in vitro rearing protocols (Peng and Jay 1977; Vandenberg and Shimanuki 1987; Aupinel et al. 2005; Silva et al. 2009; Crailsheim et al. 2013; Schmehl et al. 2016).

The results of this study emphasize the relationship between the source colony's brood survival percentage and survival percentage of individuals grafted from that colony and reared in vitro. The underlying variation in colony brood survival percentage could limit our ability to detect subtle effects of focal stressors in critical risk assessments if survival data are being compared across multiple colonies without controlling for the colony's underlying brood survival percentage. Furthermore, the underlying variation in colony brood survival percentage may result in a sampling bias in the risk assessments that are published. Presently, if the in vitro survival percentage of the untreated control is below the OECD's threshold of $70 \%$ adult emergence, the results of that risk assessment are not considered to be valid and those data are not published

Table I. Mean comparisons of the rearing environment×time point interaction effect observed for survival percentage.

\begin{tabular}{lllrrr}
\hline Rearing environment & Time point & Identifier & Survival percentage mean \pm SE & Means compared & $p$ value \\
\hline Colony & Day 11 & $i$ & $89 \pm 2.5$ & $i, i i$ & 0.002 \\
Colony & Emergence & $i i$ & $84.9 \pm 3.4$ & $i, i i i$ & 0.014 \\
In vitro & Day 11 & $i i i$ & $93 \pm 1.8$ & $i i i, i v$ & $>0.001$ \\
In vitro & Emergence & $i v$ & $84.9 \pm 3.3$ & $i i, i v$ & 0.996 \\
\hline
\end{tabular}

Data are the rearing environment, the time point at which survival was assessed, the rearing environment by time point unique identifier, the mean \pm SE survival percentage of each rearing environment by time point, an indication of which means are being compared, and the $p$ value of each comparison 

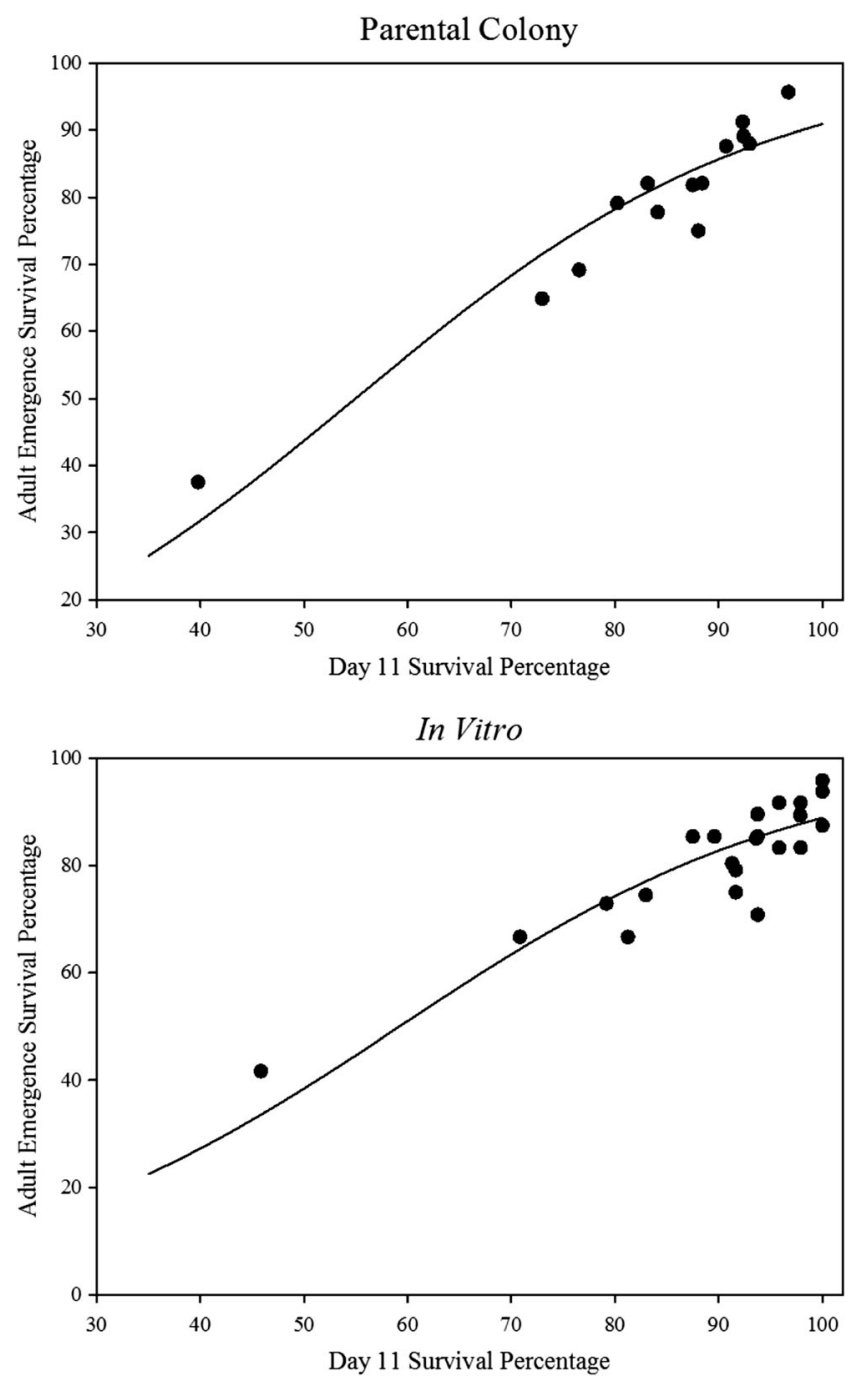

Figure 1 Predictive relationship between day 11 survival percentages and adult emergence survival percentages by rearing environment. Data were transformed back from the logit scale to percent to communicate biologically relevant values. Day 11 colony survival percentage is predictive of the adult emergence colony survival percentage (top graph) and day 11 in vitro survival percentage is predictive of the adult emergence in vitro survival percentage (bottom graph).

(OECD 2015). However, a low in vitro survival percentage may be a reflection of the source colony's brood survival percentage rather than a flaw in the trial.

To eliminate the ad hoc removal of trials that did not meet the minimum survival threshold from analysis under the current OECD standards for in vitro rearing tests, we recommend any potential source colonies to be prescreened to determine if they will be suitable or undesirable for inclusion in experiments involving in vitro rearing. One method by which prescreening could be accomplished is to graft larvae from each colony and rear them in vitro. At adult emergence, the survival rate for each colony can be calculated and only colonies that score at or above the OECD guideline of $70 \%$ adult emergence in untreated controls (OECD 2015) would be selected for use in future studies during that season. 


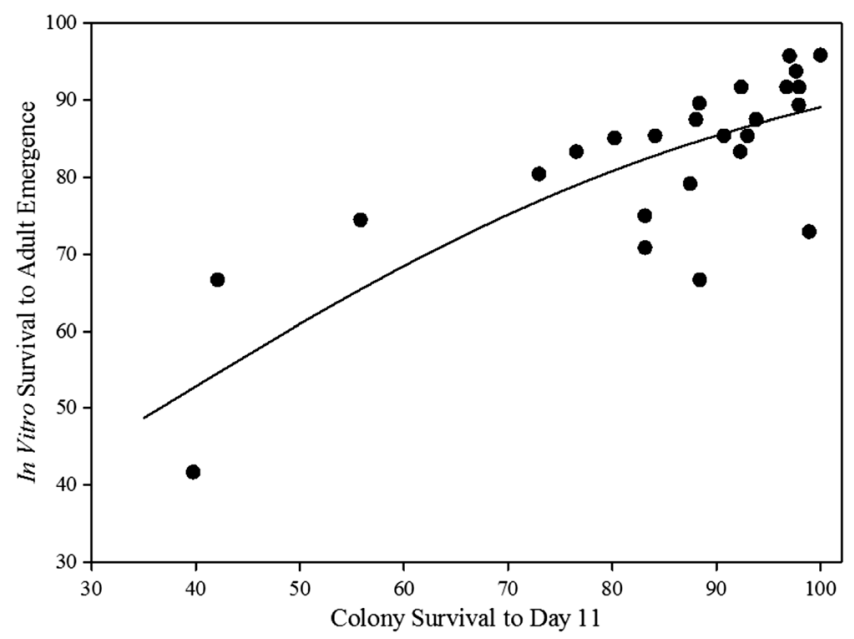

Figure 2 Predictive relationship between the D11 survival percentages in the parental hive and the adult emergence survival percentages of larvae grafted from those parental hives and reared in vitro. Data were transformed back from the logit scale to percent to communicate biologically relevant values.

Our data demonstrate that there is a predictive relationship between the day 11 survival percentages of colony-reared individuals to the adult emergence survival percentage of bees in vitroreared from that parental colony. Day 11 survival assessments for potential source colonies are simple, low-cost, and require very little time compared to rearing larvae from multiple colonies to identify colonies with high in vitro emergence rates (Human et al. 2013; Schmehl et al. 2016).

The predicted in vitro adult emergence rate of individuals grafted from a source colony that has $80 \%$ day 11 brood survival is also $80 \%$ with a $90 \%$ confidence interval of $71 \%-88 \%$. Therefore, colonies that have day 11 survival percentages of $\geq 80 \%$ are recommended as source colonies for in vitro rearing under the current OECD standards because they are most likely to foster in vitro survival percentages that met or exceed the requirements of at least $70 \%$ survival to adult emergence (OECD 2015).

In addition to the ease and costeffectiveness of assessing day 11 brood survival in the colony, we highlight that brood survival in the colony at day 11 is a more accurate indicator of adult emergence rates than the day 11 brood survival in vitro. At day 11 , brood survival was significantly higher in vitro than in the parental colony. However, there was no difference in adult survival between bees reared in the colony or in vitro. This is primarily due to a window of mortality that occurs during the in vitro process between the pupal transfer and pupation stages. We suspect this discrepancy occurs because nurse bees detect and abort larvae that are subtly abnormal in the colony (Spivak and Gilliam 1998; Ibrahim and Spivak 2006), whereas larvae reared in vitro are maintained until they fail to pupate or die during or soon after pupation.

The correlation between parental colony and in vitro survival rates suggests that genetics and/or maternal effects (Al-Lawati and Bienefeld 2009) may play a role in brood survival. However, larvae that are reared in vitro are removed from their colony within $24 \mathrm{~h}$ of hatching from their eggs. Therefore, environmental influences (e.g., pathogens) have the potential to affect eggs or larvae that are less than one-day-old prior to transfer into an in vitro-rearing trial. Considering that genetic/ maternal factors likely play a role in in vitro survival rates, care should be taken throughout the research season to ensure that source colonies do not replace their queen via swarming, supersedure, or beekeeper requeening. If a requeening event does occur, the survival rate should be reassessed for that colony before using that queenline in an in vitro rearing experiment. 
The results of this study emphasize the impact that source colony has on the in vitro survival percentage. We highlight that ad hoc removal of trials that have $<70 \%$ survival to adult emergence can be avoided by identifying source colonies that will have acceptable in vitro survival based on a simple and cost-effective strategy that assesses the survival percentage of the brood in the hive to day 11. Incorporation of source colony brood survival percentages into the analysis of risk assessments might increase the robustness of our evaluations of environmental risks by offering a more refined understanding of the change in survival caused by the experimental risk factor. Further investigations are needed to determine if and/or for how long individual colonies maintain their respective brood survival percentages over time within a season and/or across multiple seasons.

\section{ACKNOWLEDGEMENTS}

We are grateful to Daniel Schmehl and Hudson Tomé for their help with troubleshooting the in vitro rearing protocol, Cameron Jack for assistance in rearing honey bee larvae, Brandi Simmons and Emily Helton for ordering and preparing project supplies, Logan Cutts and Liana Teigan for managing healthy honey bee colonies, Vince Alderman for his diligent construction of project tools, and Edzar van Santen for statistical consultation.

\section{AUTHOR CONTRIBUTIONS}

ANM and JDE conceived this research; ANM performed experiments and wrote the paper; and JDE and ANM participated in the revisions of the paper. All authors read and approved the final manuscript.

\section{Funding information}

Funding for this project was provided by the USDA National Institute of Food and Agriculture Multistate Project (1005822) and the National Honey Board.

Le taux de survie des couvains de colonies d'abeille (Apis mellifera ) prédit le taux de survie du couvain in vitro

Apis mellifera / abeille domestique / in vitro / couvain / élevage
Die Überlebensrate von Völkern der Honigbiene (Apis mellifera) als Parameter der Vorhersage für die Überlebensrate in vitro aufgezogener Brut

\section{Apis mellifera / Honigbiene / in-vitro / Brutaufzucht}

\section{REFERENCES}

Al-Lawati H, Bienefeld K (2009) Maternal Age Effects on Embryo Mortality and Juvenile Development of Offspring in the Honey Bee (Hymenoptera: Apidae). Ann. Entomol. Soc. Am. 102, (5):881-888. doi:https://doi. org/10.1603/008.102.0514'

Alix A, Chauzat MP, Duchard S, Lewis G, Maus C, Miles MJ, Pilling E, Thompson HM, Wallner K (2010) Environmental risk assessment scheme for plant protection products Chapter 10: Honeybees-Proposed scheme. Julius-Kühn-Archiv. 423, 27

Asencot M, Lensky Y (1984) Juvenile hormone induction of "queenliness" on female honey bee (Apis mellifera L.) larvae reared on worker jelly and on stored royal jelly. Comp. Biochem. Physiol. B 78, 109-117.

Aupinel P, Fortini D, Dufour H, Tasei J, Michaud B, Odoux $\mathrm{J}$, et al. (2005) Improvement of artificial feeding in a standard in vitro method for rearing Apis mellifera larvae. B. Istectol. 58, 107-111.

Aupinel P, Fortini D, Michaud B, Medrzycki P, Padovani E, et al. (2010) Honey bee brood ring-test: method for testing pesticide toxicity on honeybee brood in laboratory conditions. Julius-Kühn-Archiv 423, 96-102.

Breed MD, Rogers KB (1991) The behavioral genetics of colony defense in honeybees: genetic variability for guarding behavior. Behav. Genet. 21, 295-303. doi: https://doi.org/10.1007/BF01065821

Brouwers EVM (1984) Glucose/fructose ratio in the food of honeybee larvae during caste differentiation. J. Apic. Res. 23, 94-101.

Buttstedt A, Ihling CH, Pietzsch M, Moritz RFA (2016) Royalactin is not a royal making of a queen. Nature 537:E10-E12.

Chauzat M-P, Faucon J-P, Martel A-C, Lachaize J, Cougoule N, et al. (2006) A survey of pesticide residues in pollen loads collected by honey bees in France. J. Econ. Entomol. 99, 253-262.

Crailsheim K, Brodschneider R, Aupinel P, Behrens D, Genersch E, et al. (2013) Standard methods for artificial rearing of Apis mellifera larvae. J. Apic. Res. 52, 1-16. doi: https://doi.org/10.3896/IBRA.1.52.1.05

De Souza DA, Wang Y, Kaftanoglu O, De Jong D, Amdam $\mathrm{GV}$, et al. (2015) Morphometric identification of queens, workers and intermediates in in vitro reared honey bees (Apis mellifera). PLoS ONE 10, e0123663. doi: https://doi.org/10.1371/journal. pone. 0123663

Delaplane KS, van der Steen J, Guzman-Novoa E (2013) Standard methods for estimating strength parameters 
of Apis mellifera colonies. J. Apic. Res. doi: https://doi.org/10.3896/IBRA/1.52.1.03

Florida Department of Agriculture and Consumer Services (FDACS) (2013) Best management practices for maintaining European honey bee colonies. http://www. freshfromflorida.com/content/download/71084 /1640892/08492.pdf. Accessed on 11 October 2017

Hendriksma HP, Härtel S, Steffan-Dewenter I (2011) Honey bee risk assessment: new approaches for in vitro larvae rearing and data analyses. Methods Ecol. Evol. 2, 509-517.

Higes M, Martín-Hernández R, Botías C, Bailón EG, González-Porto AV, Barrios L, et al. (2008) How natural infection by Nosema ceranae causes honeybee colony collapse. Environ. Microbiol. 10, 2659-2669. doi: https://doi.org/10.1111/j.1462-2920.2008.01687.x

Houle D (1992) Comparing evolvability and variability of quantitative traits. Genetics 130:195-204.

Human H, Brodschneider R, Dietemann V, Dively G, Ellis JD, et al. (2013) Miscellaneous standard methods for Apis mellifera research. J. Apic. Res. 52, 1-53. doi: https://doi.org/10.3896/IBRA.1.52.4.10

Ibrahim A, Spivak M (2006) The relationship between hygienic behavior and suppression of mite reproduction as honey bee (Apis mellifera) mechanisms of resistance to Varroa destructor. Apidologie 37, 31.

Le Conte Y, Ellis M, Ritter W (2010) Varroa mites and honey bee health: can Varroa explain part of the colony losses? Apidologie 41, 353-363.

Lebuhn G, Droege S, Connor EF, Gemmill-Herren B, Potts SG, et al. (2013) Detecting insect pollinator declines on regional and global scales. Conserv. Biol. 27, 113-120. doi: https://doi.org/10.1111/j.1523-1739.2012.01962.x

Lynch M, Walsh B (1997) Genetics and analysis of quantitative traits. Sinauer Associates Incorporated, Sunderland

Martin SJ, Highfield AC, Brettell L, Villalobos EM, Budge $\mathrm{GE}$, et al. (2012) Global honey bee viral landscape altered by a parasitic mite. Science 336, 1304-1306. doi: https://doi.org/10.1126/science.1220941

Medrzycki P, Giffard H, Aupinel P, Belzunces LP, Chauzat M-P, et al. (2013) Standard methods for toxicology research in Apis mellifera. J. Apic. Res. 52, 1-60. doi: https://doi.org/10.3896/IBRA.1.52.4.14

Meixner MD, Pinto MA, Bouga M, Kryger P, Ivanova E, et al. (2013) Standard methods for characterising subspecies and ecotypes of Apis mellifera. J. Apic. Res. 52, 1-28. doi: https://doi.org/10.3896/IBRA.1.52.4.05

Mullin CA, Frazier M, Frazier JL, Ashcraft S, Simonds R, et al. (2010) High levels of miticides and agrochemicals in North American apiaries: implications for honey bee health. PLoS ONE 5, e9754. doi: https://doi. org/10.1371/journal.pone.0009754

Nettle D (2006) The evolution of personality variation in humans and other animals. Am. Psychol. 61 , 622-631. doi: https://doi.org/10.1037/0003-066X.61.6.622

Neumann P, Carreck NL (2010) Honey bee colony losses. J. Apic. Res. 49, 1-6. doi: https://doi.org/10.3896 /IBRA.1.49.1.01
OECD (2015) Honey Bee (Apis mellifera) Larval Toxicity Test, Repeated Exposure. OECD DRAFT GUIDANCE DOCUMENT

Peng Y-S, Jay SC (1977) Larval rearing by worker honey bees lacking their mandibular glands: I. Rearing by small numbers of worker bees. Can. Entomol. 109, 1175-1180.

Peng Y-SC, Mussen E, Fong A, Montague MA, Tyler T (1992) Effects of chlortetracycline of honey bee worker larvae reared in vitro. J. Invertebr. Pathol. 60, 127-133.

Pirk CWW, de Miranda JR, Kramer M, Murray TE, Nazzi F, Shutler D, et al. (2013) Statistical guidelines for Apis mellifera research. J. Apic. Res. 52, 1-24. doi: https://doi.org/10.3896/IBRA.1.52.4.13

Rembold H, Lackner B (1981) Rearing of honeybee larvae in vitro - effect of yeast extract on queen differentiation. J. Apic. Res. 20, 165-171.

Scheiner R, Abramson CI, Brodschneider R, Crailsheim K, Farina WM, et al. (2013) Standard methods for behavioural studies of Apis mellifera. J. Apic. Res. 52 , 1-58. doi: https://doi.org/10.3896/IBRA.1.52.4.04

Schmehl DR, Tomé HVV, Mortensen AN, Martins GF, Ellis JD (2016) Protocol for the in vitro rearing of honey bee (Apis mellifera L.) workers. J. Apic. Res. 55, 113-129. doi: https://doi.org/10.1080 /00218839.2016.1203530

Sheppard WS (1989) A history of the introduction of honey bee races into the United Sates: Part II. Am. Bee J. 129, 664-667.

Silva IC, Message D, Cruz CD, Campos LAO, SousaMajer MJ (2009) Rearing Africanized honey bee (Apis mellifera L.) brood under laboratory conditions. Genet. Mol. Res. 8, 623-629.

Spivak M, Gilliam M (1998) Hygienic behaviour of honey bees and its application for control of brood diseases and Varroa . Bee World 79, 124-134. doi: https://doi. org/10.1080/0005772X.1998.11099394

Steinhauer NA, Rennich K, Wilson ME, Caron DM, Lengerich EJ, et al. (2014) A national survey of managed honey bee 2012-2013 annual colony losses in the USA: results from the Bee Informed Partnership. J. Apic. Res. 53, 1-18. doi: https://doi.org/10.3896 /IBRA.1.53.1.01

Vandenberg JD, Shimanuki H (1987) Technique for rearing worker honeybees in the laboratory. J. Apic. Res. 26, 90-97. doi: https://doi.org/10.1080 /00218839.1987.11100743

vanEngelsdorp D, Speybroeck N, Evans JD, Nguyen BK, Mullin C, et al. (2010) Weighing risk factors associated with bee colony collapse disorder by classification and regression tree analysis. J. Econ. Entomol. 103 , 15171523. doi: https://doi.org/10.1603/EC09429

Wittmann D, Engels W (1981) Development of test procedures for insecticide-induced brood damage in honeybees. Mitt. Dtsch. Ges. Allg. Angew. Entomol. 3, 187190.

Woyke J (1963) Rearing and viability of diploid drone larvae. J. Apic. Res. 2, 77-84. 